\title{
EFFECTIVENESS OF THE STRATEGY OF SIMILARITIES IN THE LEARNING OF THE WOMEN'S FASHION FIGURE DRAWING FOR SPECIALIZED STUDENTS
}

Karama Thabet Hassan AL-SHEIKH *

Department of Garment and Textile, Faculty of Home Economics, Helwan University, Egypt

\begin{abstract}
With the emergence of the idea of modernity at the beginning of the twentieth century, it was found that there is an interaction and complementarity between art and technology (technology), which combines what is useful and what is beautiful, and therefore design links between art, technology and science, meaning that design needs adjustments through the logic of science. And the trends of ethics and their connection with custom and society, and it needs the aesthetic touch through art, and the design must be implemented through technology, and it must carry aesthetic values in light of the technical standards on the practical and apparent level of design.
\end{abstract}

Keywords

Effectiveness, Strategy, Similarities, Learning, Women's Fashion, Figure Drawing.

\section{Introduction}

Costume design is An arrangement process for a group of vocabulary representing the form language used by the designer to take the form that he deems appropriate for artistic work or design, these vocabulary includes the elements and foundations of design, and drawing mannequins (whether children, women or men mannequins) in addition to the different clothing surfaces, as well as materials with multiple effects And the formulation of these vocabulary needs a creative sense in order to achieve coherence and consistency within the design.

An innovative conscious designer is the one who thinks about the external form of the design to give women a unique look, and is considered successful when his designs are authentic and compatible with the woman's body, and the designer puts in his mind at first glance the shape before starting the design for the body, (Jawdeh, Abdulaziz et al.2004).

Many studies have dealt with women's fashion design, which depends on women's mannequins in drawing those designs, including two studies by (Zaghloul, Sahar - 2006) the first entitled The effectiveness of a proposed program in women's fashion design and measuring its impact on the basic concepts and skills of students of the clothing and textile department, and another Entitled the effectiveness of using the educational video in developing basic concepts and skills in designing women's fashion among students of the clothing and textile department. The first study included measuring knowledge And the skills for the program of the women's fashion design course for specialized students, while the second study included measuring the

* Corresponding author: homeecon@helwan.edu.eg 
knowledge and skills for teaching female mannequin drawing using an educational method that is the educational video and not with a modern strategy as is the case in the current study, in addition to the steps followed in explaining the mannequin drawing in that study Clearly prolonged, which causes difficulty in learning, the results of the two studies reached a preference for the two experimental groups on the cognitive and skill level.

The human body is the first thing that a fashion design artist deals with, as it is the basis on which to build his artistic work, and a student specializing in fashion design must have an accurate knowledge and understanding of the characteristics of the human body of women.

It enables him to deal with him to present design innovations and devise new dimensions and innovative ideas in fashion design, and the knowledge and understanding of the student increases with the study of the anatomy of the human body, which helps to accurately identify the external dimensions of the body and the anatomical characteristics of a woman's body in terms of building and distribution of muscles and the skeleton that is the basis and determinant. The first is to build the body and places of joints and fats whose accumulation varies in different places in the body, but also varies in one body. In some bodies there are large aggregations in a part of it with less fat in the rest of the body, and this relative difference in the amount of fat in the various bodies results in bodies And many physical patterns even for bodies that belong to the same size, and a student of the proportions of the human body realizes the accuracy and miracles that God created Almighty God by those proportions, the body can be drawn considering that the height of the head is from the top

Below the chin is the unit of measurement for drawing the rest of the body, and this proves that the body is subject to a precise engineering system, and covers all the components of the body, the skin, as it is the outer covering of the body that the fashion designer deals with in the first place, and a good designer is the one who designs clothes that meet all his aesthetic, functional and physiological requirements for this The outer covering of the woman's body (Shukry, Najwa and others 2011). There are studies that dealt with the mannequin drawing based on the anatomical study of the human body and dealt with different strategies from the current research, including the study (Mouawad, Yusry - 2016) which dealt with the same topic of the current research in terms of drawing the mannequin, but dealt with the mannequin, while using a different strategy, which is the strategy of "learning". Al Maqloub "through a teaching unit and measuring its effectiveness in terms of knowledge and skills for students of the third year clothing and textile division through two groups, one of them experimental And the other is a control. The results showed that there are fundamental differences between the post application of the two groups in favor of the experimental group that studied the flipped 
learning strategy. Among the studies that were exposed to drawing the mannequin is a study (Drago2000-Shery), which aimed to measure the effectiveness of the experimental teaching method, and the teaching based on explanation and interpretation in learning drawing The female mannequin and the comparison between the two teaching methods for a sample of (158) students, research tools, trends scale, achievement test, last skill and note card, the results showed that there were no statistically significant differences between the two teaching methods in drawing mannequin as for the study (Solomon, Kifaya and Shukry, Nagwa - 1990) It was one of the first studies that dealt with female mannequin drawing, but using a different strategy from the current research It is a self-learning method for (52) students of the fourth year of the clothing and textile division, and the results resulted in the superiority of the experimental group that studied in this method compared to the experimental group that studied in the traditional way, and the current research used a modern strategy different from the strategies used in previous studies.

And the student of the art of fashion design must have a complete knowledge and perception of all the previous details of the external body of the woman in order to be prepared for the design of this body with awareness and an understanding of the physiological factors, the most important of which are comfort and movement as well as the functional and aesthetic factors in the design in addition to an understanding of the physical changes with advancing age, and on the other hand, understanding Psychological impact In addition to dealing with physical defects intelligently, the psychological person should have this determination (Shukry, Najwa et al 2011).

- It is difficult to present a single model for the ideal body, as the standards of beauty, consistency and typical textures differ from time to time, and depend on what fashion dictates at a particular time, in addition to personal taste, and there are many differences for the external shape of a woman's body and the shape and size of the outside, so each structure has its own shape and distinctive character The shape of the body in the countryside differs from that in urban areas, and it differs in the coastal areas from the desert areas, and the structural form may differ from one people or sex to another and the genetic factor, and even differ according to the economic and social level.

And the social to which the individual belongs, his style and behavior in life, his food habits, the nature of movement, activity and hereditary factors, also the typical proportions of the body change over the centuries and from time to time, because the human body is characterized by great flexibility that enables it to be adapted into an infinite number of forms, each form considered in its age Most desirable integral scales (Shukri, Najwa - 2011) 0 A fashion student 
should take into account all these matters and topics related to the human body because they are related to the correct drawing of a female mannequin and with accurate measurements. The differences in the dimensions of a woman's body have aroused the thought and interest of garment producers throughout the ages, as the disparate qualities between the styles of the bodies were the engine for the design thinking to proceed from the quality of that difference in the dimensions of the body And trying to formulate it in a manner consistent with the aesthetic ideals of each period of time, but sometimes the difference is an advantage so that the new design vision of the clothes stems from that difference. (Abdul Majeed, Naglaa - 2008).

Female mannequin drawing is one of the important lessons taught by students specializing in the clothing department of the third division and training in mastery of drawing, where students draw mannequins, then dress them with design ideas borrowed from one of the sources of quotation, and then color designs with the effects of different materials, and the traditional learning method is followed in this This requires time and effort during learning, especially with the limited number of skilled teachers in this field It is noticeable recently that the gap between the educational educational needs of students and the professional capabilities of teachers and their small number is widening. On the other hand, it is the responsibility of those in charge of the educational process to keep pace with modern and rapid technological developments. Therefore, the need for employing many modern educational means, methods and strategies has increased to seek to develop students 'skills. On achievement, thinking and research in order to reach the educational level appropriate for civilized nations.

The development in any aspect of life always aims to reach the developed thing to the best image in order to perform the purpose required of it efficiently, and among the aspects covered by the development educational trends and modern educational curricula Modern and that in many countries of the world, especially the developed ones, as they witnessed many developments in their objectives, content, and methods of teaching them, in line with the requirements of society.

The similarities strategy is considered one of the interesting modern strategies that facilitate the student's understanding of the information and skills presented to him and have a positive effect on him. It is a method of teaching based on explaining and clarifying phenomena by comparing them with other familiar phenomena and concepts. (Al-Qatrawi, Abdulaziz Jamil 2010)

As both (Afaneh, Ezzo, and Al-Jaish, Yusef - 2009) see that the strategy of similarities is a bridge between the previous familiar concepts and the concepts unfamiliar to the student.

This helps the student to create new cognitive experiences of unfamiliar abstract concepts, and 
it is also a useful strategy in modifying the misconceptions of the students' acquired concepts, he adds (Abdul Salam, Mustafa 2001)

It linked two topics of equal level of universality and degree of difficulty and combined them with common elements with the aim of making the unfamiliar familiar.

Among the studies that dealt with the topic of similarities are the study (Al-Agha, Iman - 2007) entitled the effect of using the similarities strategy in acquiring and retaining scientific concepts among ninth grade students in Gaza, and the study (Al-Qatrawi, Abdulaziz Jamil - 2010) on the impact of the similarities strategy in developing science processes and thinking skills. Contemplation onScience among students of the eighth grade basic, as well as the study (Attia, Afaf Attia - 2003), which focused on researching the effect of using the strategy of similarities in the development of achievement and scientific thinking among first-grade students through the subject of physics. The results of the three studies concluded that there are statistically significant differences For the benefit of the experimental groups who studied with the strategy of similarities compared to the control groups who studied by traditional methods, as the strategy helped to build knowledge and acquire skills, and the perception of the similarities and the similarities and differences between them contributed to the realization of the student's mind and increased interaction and positive effect on him during learning.

Hence the idea of the research, which is the use of one of the modern strategies in learning especially after studies have proven the success of this strategy in educational fields. It is a strategy of similes that helps students to acquire information and acquire skills by converting unfamiliar information to them into familiar and meaningful information. This strategy was applied in the field of fashion design, in particular on one of the basic lessons. The task that the student who specializes in fashion should learn, which is the lesson of female mannequin drawing by imagining every part of the mannequin and resembling geometric shapes, in the sense of imagining every part of the mannequin to be drawn (the part is unfamiliar) 'and similar (to a familiar part) which is the geometric figure So that the student can imagine the parts of the mannequin and then draw them in a short time and in few and simple steps that do not take long to draw.

\section{Research Problem}

The research problem can be identified in the following questions:

1. What is the possibility of using the strategy of similarities in learning a lesson from the fashion design course (mannequin) Women?

2. What is the effectiveness of applying the similarities strategy to students acquisition of the knowledge of the lesson covered? 
3. What is the effectiveness of applying the strategy of similes on students' acquisition of the skills included in the lesson dealt with?

4- What are the students' opinions towards teaching (female mannequin drawing) using the simile strategy?

\section{Research Aims}

1- Teaching the students of the third year of the clothing and textile division, one of the lessons of the fashion design course, which is a lesson (drawing of female mannequins) according to the strategy of similes.

2- Measuring students 'achievement of concepts, information and facts contained in the lesson (female mannequin drawing) designed according to the strategy of similes.

3- Measuring the students 'acquired skills from learning a lesson (drawing the female mannequin) according to the simile strategy.

4. Forming a positive attitude among students towards teaching with a strategy of similarities.

\section{Research Importance}

1- Trying to raise the level of the graduate specializing in clothing and textiles through the application of a modern strategy in teaching.

2. Contribute to updating the method of education in the field of fashion design in line with modern trends in teaching.

3. It has drawn the attention of officials and those in charge of the educational process to the need to introduce modern strategies in education, especially those related to skills.

\section{References}

1. Al-Agha, Eman. (2007) "The effect of using the strategy of similarities in acquiring and retaining scientific concepts among ninth-grade students in Gaza." Unpublished master's thesis, Department of Curricula, College of Education, Islamic University of Gaza.

2. Al-Banna, Hamdy. (2000) "The Effectiveness of Teaching with Strategies of Isomers in Achievement and Solving Chemical Problems of High School Students in Light of Some Mental Variables, Fourth Scientific Conference, Egyptian Society for Scientific Education, Ain Shams University.

3. Al-Qatrawi, Abdulaziz Jameel. (2010), "The Impact of the Isomorphic Strategy on the Development of Science Processes and Reflective Thinking Skills in Science among Eighth Grade Basic Students", Unpublished Master Thesis, Department of Curricula, College of Education, Islamic University of Gaza.

4. Gouda, Abdel Aziz and El-Khouly, Mohamed and El-Demerdash, Doha (2004), "Basics of Fashion Design," Al-Tawfiq Al-Model House for Printing. 
5. Hamida, Amani. (2010) Self-Inquiry, Similarities and Teaching Social Studies, First Edition, Al Arabia for Advanced Curriculum and Software, Egypt.

6. Darwaza, Afnan. (2000) “Theory in Teaching and its Practical Translation”, Dar Al-Shorouk Press.

7. Rafa'i, Wafaa (2002) "The Effect of Using Discovery Learning Method Using Contradictions on the Development of Scientific Concepts and Some Science Processes for First-Year Preparatory Pupils," Master Unpublished, College for Girls, Ain Shams University 8. Zaghloul, Sahar. (2006) "The effectiveness of using the educational video in developing basic concepts and skills in designing women's fashion among students of the clothing and textile department."

9. Soliman, Kifaya and Shukry, Najwa (1990). "The Effectiveness of Using Programming in Learning to Draw the Basic Body of Fashion (The Mannequin)" Journal of Home Economics. 10. Lehman, Kifaya and Shukry, Najwa. (1993) "Fashion design and modeling on the mannequin", Arab Thought House.

11- Shukry, Najwa and Al-Zaftawi, Hanan and Abboud, Doaa (2011), "Modern techniques in preparing mannequins for formation," 2nd edition, The World of Books.

12. Abdel Salam, Mustafa. (2001) "Modern trends in science education," Dar Al-Fikr Al-Arabi. 13. Abdel-Majeed, Naglaa. (2008) "The effect of different dimensions of the girls' body on design in the fashion industry, "unpublished $\mathrm{PhD}$ thesis, Faculty of Home Economics, Helwan University.

14. Obaidat, Thouqan and Abu Al-Sameed, Suhaila (2007). Strategies in the Twenty-first Century Teacher Guide

And the educational guide "Dar Al Fikr for publication and distribution.

15. Attia, Afaf Attia. (2003) The effect of using contradictions and similarities in developing achievement and scientific thinking among first-grade students through the subject of physics, an unpublished master's thesis, Faculty of Education in Ismailia, Suez Canal University.

16- Afaneh, Ezzo, and Al-Jaish, Yusef (2009). "Teaching and Learning with the Two Sided Brain”, First Edition, House of Culture for Publishing, Amman, Jordan.

17. Kattame, Youssef, et al. (2000) “Teaching Design," 1st Edition, Dar Al-Fikr for Printing and Publishing.

18 Moawad, Yusra. (2016). "The Effectiveness of a Teaching Unit for Mannequin Drawing for Men's Fashion by Learning Flipped Using Multimedia," Science and Arts, Helwan University, Vol. (28), No. (3) July.

19. Dance, S. \& et-al. ( 2005). The role of studentgenerated analogies in pro- muting conceptual 
for undergraduate che- mystery students, Science \& Technological education, V.23, N.2.

20. Drago ,Shery.(2000) Fashion and illustration, London

21. Robenta, R. (1999). Testing of Effectiveness of an Ubstryctuibakorigram Related to Apparel Design. California State University, U.S.A.

22. Sanjak Ibrahim Mustafa MUHAMMAD, Naglaa Ezzat Ahmed MAHMOUD, CREATING MODERN DESIGNS FOR NARROW INTERIOR SPACES INSPIRED BY

THE ART OF ORIGAMI, International Journal of Design and Fashion Studies, Vol. 1, No. 1, 2018, pp. 13-16.

23. Dina Ahmed NAFADY, CREATIVE INTEGRATION OF VARIOUS PRINTING TECHNIQUES AND THE AESTHETICS OF CONTEMPORARY SAUDI PLASTIC ART TO CREATE PRINTED FASHION DESIGNS, International Journal of Design and Fashion Studies, Vol. 1, No. 1, 2018, pp. 17-20.

Received: July 3, 2018

Accepted: September 9, 2018 